\title{
David Suarez* \\ Nature at the Limits of Science and Phenomenology
}

https://doi.org/10.1515/jtph-2019-0004

Published online December 26, 2019

Abstract: Kant and Heidegger argue that our subjectivity escapes scientific explanation, while also providing the conditions that enable it. This understanding of the relationship between subjectivity and science places limits on the explanatory scope of the sciences. But what makes transcendental reflection on the structure of subjectivity possible in the first place? Fink argues that transcendental philosophy encounters its own limits in attempting to characterize its own conditions of possibility. I argue that the limits of science and transcendental philosophy entail that nature cannot be conceived as a specific object, or as a totality of objects in the world, but only as the ontological ground of phenomenal manifestation in general. Nature is not identical with anything discoverable in either science or phenomenology; it is, rather, the origin from which discovery of phenomena proceeds.

Keywords: Immanuel Kant, Martin Heidegger, Eugen Fink, Maurice MerleauPonty, naturalism.

\section{Introduction}

In this paper, I will argue that the reflective limits of transcendental philosophy are the key to understanding what it means for nature to be the ontological ground of both natural science and transcendental reflection. Nature cannot be identified solely with what shows up in experience of the world, i. e., with beings that are manifest in either world-experience or transcendental reflection, for nature is never simply coincident with what is manifest. It is, instead, a condition of the manifestation of beings, whose own mode of being is to be identified with processes of phenomenal manifestation in general. Nature does not simply consist in what is manifest to consciousness-in some worldly being, in the totality of worldly beings, or even in a manifest "transcendental being"-rather, it consists in processes of manifestation that simultaneously constitute transcendental

*Corresponding author: David Suarez, Department of Philosophy, University of Toronto, 170 St. George St., 4th Floor, Toronto, Ontario M5S 1A1, Canada, E-mail: dave.suarez@mail.utoronto.ca. https://orcid.org/0000-0001-9037-7239 
subjectivity and the world as a unified domain. In this way, phenomenology finds a place for nature as a principle of ontological grounding, allowing for what I will call a phenomenological naturalism. ${ }^{1}$

How does this form of naturalism compare to other, more standard forms of naturalism? In §2 and §3, I explain why Kant and Heidegger would reject a metaphysical naturalism which claims (i) that the natural sciences themselves exhaustively determine the range of natural objects, and (ii) that these natural objects are the only ones that exist. Kant must reject this thesis because his transcendental idealism entails that we can have no theoretical justification for the denial of supernatural or supersensible things in themselves, while, by the same token, we also lack theoretical justification for affirming their existence. ${ }^{2}$ Heidegger, too, must reject metaphysical naturalism because Dasein's being-in-the-world constitutes a way of being which is not and cannot be disclosed by any natural science. How do things stand for these two figures with respect to methodological naturalism? Both Kant and Heidegger would reject Quine's understanding of naturalism, which requires that philosophy limit itself to the justificatory methods of the natural sciences. Quine writes that

Naturalistic philosophy is continuous with natural science. It undertakes to clarify, organize, and simplify the broadest and most basic concepts, and to analyze scientific method and evidence within the framework of science itself. (1995, pp. 246f.)

If "continuity" requires philosophy to restrict itself to the methods of science, then Kant and Heidegger are not methodological naturalists. However, if "continuity" requires only the logical compatibility of the justificatory methods of philosophy

1 A number of authors inspired by Heidegger and Merleau-Ponty have defended conceptions of nature similar to the one I develop here (see, for example, Bannon 2014; Foltz 1995; Glazebrook 2000; Haar 1993; Storey 2015; Zimmerman 2003). I arrive at a phenomenologically-informed conception of nature by a unique route, however, following a path from Kant through to Heidegger, Fink, and Merleau-Ponty, using the history of the development of conceptions of nature in transcendental philosophy and phenomenology to address (i) problems internal to standard science-based naturalisms (problems Kant had already identified), and (ii) problems internal to transcendental phenomenology (problems I discuss in the sections on Heidegger, Fink, and Merleau-Ponty below). In particular, I set aside axiological and theological considerations in motivating my conclusions; my arguments are not premised on the need to provide a theoretical grounding for an environmental ethics, or a desire to find a place for spiritual life within a naturalistic ontology. That said, it speaks for the views I share in common with these previous authors that one arrives at similar ontological "solutions" regarding the nature of nature even when one focuses on a different set of problems.

2 While Kant argues that we have practical justification for belief in God, freedom, and the immortality of the soul, he is clear that practical justification of this kind is not sufficient to ground metaphysical knowledge-as he puts it in the B-edition Preface, "I had to deny knowledge in order to make room for faith" (1998, p. 117). 
and science, then Kant and Heidegger might qualify as methodological naturalists since they argue for the complementarity of the justificatory methods of philosophy and science. They accept the validity of at least some natural scientific methods of justification, while adding that these methods stand in need of a deeper justification that only philosophy can provide.

Thus, Kant and Heidegger take the domain of the natural to be opened to us in a way that enables natural scientific inquiry, while claiming that the mode of being of this opening cannot be understood using the methods and the metaphysical principles of a natural science. Instead, transcendental philosophy and phenomenology purport to explain the possibility of the natural sciences in a way that the sciences are not equipped to do on their own. While Kant and Heidegger are in agreement on this point, Heidegger argues in Kant and the Problem of Metaphysics that Kant's transcendental philosophy is “methodologically naïve” (1997, p. 200) with respect to the ontological conditions of its possibility. In $\S 4$, I examine this criticism of Kant, explaining how it motivates Heidegger's phenomenological ontology of subjectivity as being-in-the-world.

What makes phenomenological reflection on the transcendental conditions of world-experience possible? In asking this question, we reach another explanatory limit, a limitation on the ability of transcendental-phenomenological reflection to make its own conditions of possibility phenomenally manifest. In the Sixth Cartesian Meditation, Eugen Fink, Husserl's student and collaborator, argues that reiterating transcendental reflection on conditions of the possibility of experience at the level of the transcendental cognitions pushes philosophy to the limit of what can be given in experience. If the transcendental conditions of world-experience are prior to, and make possible our access to worldly beings, then these conditions cannot be worldly beings themselves, for then phenomenology would need to posit further conditions of possibility in order to explain how we have access to the first set of transcendental conditions, leading to a regress. This seems to leave phenomenology with a methodological problem: how can it account for its own conditions of possibility if these conditions cannot show up for us in reflection as beings? I explain the structure of this methodological worry using resources from Fink in $\S 5$, and suggest an answer to the worry in $\S 6$.

To begin, however, let's turn now to a closer examination of two areas in which Kant and Heidegger rein in the metaphysical and methodological claims of naturalism: physics, and the study of subjectivity. ${ }^{3}$ Of these two, the second is of

3 Heidegger's development of the concept of being-in-the-world should be understood as both a departure from older conceptions of subjectivity, and as an existential-phenomenological development of those conceptions. 
deeper significance, for it is the subjectivity involved in scientific practice that explains why natural science has limits: the limits of natural science, for Kant and Heidegger, correspond to a lacuna or blind spot of science with respect to the mode of being of the very subjectivity that makes scientific understanding possible in the first place.

\section{Kant on Physics}

In Metaphysical Foundations of Natural Science, Kant distinguishes between two senses of "nature". In the first sense, a thing's nature is its essence, the inner principle of its possible determinations, which makes it the kind of thing that it is. In the second sense, nature is "the sum total of all things insofar as they can be objects of our senses, and thus also of experience" (2002, p. 183). In the first sense, "nature" refers to a thing's essence; in the second sense, "nature" refers to a totality of things.

For Kant, to have an essence or inner principle is to fall under a law. Thus, Kant tells us, in a discussion from the Prolegomena (which parallels his discussion in Metaphysical Foundations), that "Nature is the existence of things, insofar as that existence is determined according to universal laws" (2002, p. 89). Kant infers from this that a thing's nature cannot be a feature of its existence considered as a thing in itself, for "If nature meant the existence of things in themselves, we would never be able to cognize it, either a priori or a posteriori" (2002, p. 89). "Nature" cannot refer to the features of things in themselves, because this would make nature unknowable: the faculty of understanding lacks the power to determine things in themselves a priori, and experience cannot discover the necessity which belongs to laws a posteriori.

"Nature," in the first sense, is a formal notion that refers to the inner principles that constitute the possible determinations of objects and, thereby, the laws they obey (2002, p. 183). By contrast, "nature," in the second sense, is a material notion, referring to an actual set of objects that constitute a totality-nature as the "sum total of all objects of experience" (2002, p. 89). In virtue of possessing a nature in the first sense (an essence), the objects we study in empirical natural science belong to nature (a totality) in the second sense.

Since, for Kant, the defining feature of nature is law-governed existence as cognized in possible experience, it follows that natural science can only be concerned with the laws pertaining to objects considered as phenomena. Some of these laws concern inner experience, some concern outer experience, and some both. The laws of inner experience are the laws of psychology; the laws of outer experience are first and foremost the laws of physics, but include the laws of other 
sciences which study material bodies, such as chemistry. ${ }^{4}$ Focusing on the content of physical science, we find impure laws, which Kant agrees we can only come to know a posteriori, through experience, but also "a pure natural science, which, $a$ priori and with all of the necessity required for apodictic propositions, propounds laws to which nature is subject” (2002, p. 89). The laws of pure natural science apply necessarily to all objects of experience whatsoever. Kant gives as examples "that substance remains and persists, that everything that happens always previously is determined by a cause according to constant laws, and so on" (2002, p. 90). The existence of nature, in Kant's second sense as the "sum total of all objects of experience", presupposes the laws of pure natural science as a priori principles constituting "a system of nature, which precedes all empirical cognition of nature and first makes it possible” (2002, p. 100).

Kant argues in the Transcendental Deduction that this "system of nature" finds its source in the necessary unity of conscious experience. Experience, taking the form of a system of objectively valid judgments, necessarily involves the deployment of certain concepts under which we bring our sensible intuitions: these are the pure concepts of the understanding. As Kant puts it towards the end of the Transcendental Deduction in the A-edition: "we ourselves bring into the appearances that order and regularity that we call nature, and moreover we would not be able to find it there if we, or the nature of our mind, had not originally put it there" (1998, p. 241). Continuing a little later on, Kant adds that

The understanding is thus not merely a faculty for making rules through the comparison of the appearances: it is itself the legislation for nature, i.e., without understanding there would not be any nature at all, [...] for appearances, as such, cannot occur outside us, but exist only in our sensibility. $(1998, \text { p. } 242)^{5}$

4 In Metaphysical Foundations of Natural Science, Kant says that "What can be called proper science is only that whose certainty is apodictic; cognition that can contain mere empirical certainty is only knowledge improperly so-called" (2002, p. 184). On this basis, he argues that chemistry (2002, p. 184) and psychology (2002, p. 186) qualify only as "improper" sciences, since the laws belonging to them can only be determined on the basis of experience, lacking any pure parts that are determinable a priori, as in the case of physics. See McNulty (2017) for a detailed discussion of Kant's views on chemistry and the distinction between "proper" and "improper" natural sciences.

5 Why do these passages appear only in the A-edition? I would argue that these changes do not reflect a change in Kant's view, but instead a concern that his wording in the A-edition could be read all too easily as supporting empirical idealism, rather than the transcendental idealism he intended. In both editions of the Critique of Pure Reason, Kant intends to portray the dependence of nature on subjectivity as a transcendental dependence, not an empirical dependence. Kant's removal of these passages (and the two quoted below) in the B-edition reflects a change in his way of expressing the same view, not a change of view. 
Clearly, this will place limits on the ambitions of natural scientific explanation. Because physics is the study of the laws of outer appearance, and not the study of what exists in itself, Kant must deny any attempt to identify fundamental physics (or any other natural science) with the study of the fundamental structure of reality as it is in itself. Moreover, since physics is a determination of the "system of nature" in general, and since that system depends on the application of the pure concepts of the understanding, the justificatory practices of natural science as a whole stand in need of supplementation by transcendental philosophy, since we would be unable to account for the lawfulness of experience, and $a$ fortiori, the lawfulness of nature as "sum total of the objects of experience," without a transcendental account of the operations of the understanding in transcendental synthesis. Thus as Kant puts it,

as exaggerated and contradictory as it may sound to say that the understanding is itself the source of the laws of nature, and thus of the formal unity of nature, such an assertion is nevertheless correct and appropriate to the object, namely experience. (1998, p. 242)

Nevertheless, Kant's conception of physics is still open to empirical, and even experimental, methods. As he admits,

empirical laws, as such, can by no means derive their origin from the pure understanding... But all empirical laws are only particular determinations of the pure laws of the understanding, under which and in accordance with whose norm they are first possible... (1998, pp. 242f.)

So, for example, as Kant notes in $§ 15$ of the Prolegomena, the concepts of motion, impenetrability, and inertia, are subject to a posteriori determination by experience (2002, p. 90). In spite of this, they remain determinations of a more general framework, the system of nature, which is brought into experience by the operations of the understanding.

Kant, then, must reject metaphysical naturalism regarding the objects of physics, since physics does not discover the natures of its objects through empirical inquiry alone, but requires further non-empirical support in the form of transcendental philosophy. Moreover, since the objects of physics are appearances, and not things in themselves, Kant would deny that we have justification for the metaphysical claim that physical objects are the only ones that exist, since it is at least thinkable that there could be supersensible or supernatural entities, even though we are systematically unable to cognize such entities for the purposes of speculative metaphysics. $^{6}$

As noted earlier, if continuity between philosophy and natural science requires the exclusion of all justificatory methods aside from those internal to natural

6 Though see note 2, above, regarding practical justification. 
science itself, then Kant fails to qualify as a methodological naturalist. On the other hand, if continuity requires only a logical compatibility of methods, then Kant may still qualify, since none of his claims regarding nature are intended to conflict with those of physics, provided that physics is considered solely as the study of the laws of outer appearance. ${ }^{7}$

\section{Heidegger on Physics}

Summarizing Kant's view of the relationship between the ego and the pure concepts of the understanding, Heidegger writes that,

As ground of possibility of the "I think," the ego is at the same time the ground and the condition of possibility of the forms of combination, the categories. Since these categories are conditioned by the ego, they cannot be applied in turn again to the ego in order to apprehend it. That which conditions absolutely, the ego as the original synthetic unity of apperception, cannot be determined with the aid of what is conditioned by it. (1988, p. 144)

Heidegger is largely in agreement with Kant regarding the explanatory priority of subjectivity, taking it as a transcendental condition of the possibility of physics. Like Kant, Heidegger takes physics to be justified in its claims about the objects in its domain of inquiry, but incomplete as an account of how we have access to such objects in the first place: the justificatory methods of physics must be supplemented by an a priori examination of the knower and its relation to nature.

For Heidegger, our mode of being as Dasein makes beings intelligible as beings-it is a transcendental condition of the possibility of an understanding of being in general. This is to say that our access to beings, our openness to them, whatever makes them intelligible such that we can say that they are or are not, that they exist or not, just is our mode of being as Dasein.

Moreover, as we discover in Division Two of Being and Time, Dasein's beingin-the-world is constituted most fundamentally by temporality [Temporalität], a unity of temporal horizons in which we are "always already" enmeshed such that we find ourselves in the midst of an interwoven past, present, and future. Since these temporal horizons form the ground and condition of intelligibility for any being whatsoever, the intelligibility of temporality itself cannot be understood on the basis of some further being standing outside of temporality, since such a being would be, ex hypothesi, unintelligible.

7 More could be said about whether Kant's a priori commitment to Euclidean spacetime makes his rehabilitation as methodological naturalist impossible given the present consensus in physics that spacetime is non-Euclidean; I leave that question open here. 
For the moment, however, let us return our focus to physics, in order to see how Heidegger understands the dependence of physics on Dasein, and how these details bear on the question of Heidegger's naturalist credentials.

Pivotal to this question is Heidegger's "existential conception of science," which "understands science as a mode of existence and thus as a mode of being-inthe-world which discovers or discloses beings or being” (2010, p. 340). This view of science-as a way in which human beings come to inhabit their world-contrasts starkly with the much more familiar "logical" conception of science according to which science is conceived as a network of interconnected propositions that have been validated epistemologically (2010, p. 340). The logical conception of science abstracts from the practice of science and its embeddedness in human projects, focusing instead on its "products," the results of science, conceived as observationally-validated and propositionally-structured theories.

What Heidegger wants to highlight in developing this contrast between logical and existential conceptions of science is that a philosophy of science that focuses only on theories and their epistemic validity is impoverished as a view of what science is; first, because it does not capture the full mode of being of science as a concrete activity, and second, because it misses the fact that the intelligibility of scientific theories is dependent on the mode of being of Dasein, through which all beings are discovered. Such a philosophy of science abstracts from scientific practice entirely, and, in doing so, leaves unexamined how such a practice could constitute a form of openness to phenomena in the first place.

What does understanding science as a mode of being of Dasein entail? To answer this question, Heidegger turns in Being and Time to mathematical physics:

The classic example for the historical development of a science, and even for its ontological genesis, is the origin of mathematical physics. What is decisive for its development lies neither in its higher evaluation of the observation of "facts," nor in the "application" of mathematics in determining events of nature, but the mathematical project of nature itself. (2010, p. 345)

For Heidegger, then, the key features that lead to the development of mathematical physics are neither its focus on empirical observations rather than a priori reasoning, nor its efforts to predict events with ever-greater precision. Rather, what is decisive is the ontological understanding of nature embodied in such scientific practice:

This project discovers in advance something constantly objectively present (matter) and opens the horizon for the guiding perspective on its quantitatively definable constitutive moments (motion, force, location, and time). Only "in the light of" a nature thus projected can something like a "fact" be found and be taken in as a point of departure for an experiment defined and regulated in terms of this project. [...] What is decisive about the mathematical project of nature is again not primarily the mathematical element as such, but the fact that this project discloses a priori. (2010, p. 345) 
Heidegger says here that the a priori condition for mathematical physics is a "project" of Dasein, a project in virtue of which beings can be accessed in the familiar terms of physical theory. ${ }^{8}$ This projection of nature is not a mere imposition on reality, but a form of transcendence, a form of openness to the world, a disclosure, that makes objects available in terms of quantitative and qualitative determinations which they really, and in themselves, possess.

Heidegger describes the upshot of Kant's conception of nature in similar terms in Kant and the Problem of Metaphysics:

the "previously projected plan" of one nature in general determines in advance the constitution of the being of beings, to which all questions that are investigated should be capable of being related. This preliminary plan of the being of beings is inscribed within the basic concepts and principles of the science of nature to which we already referred. Hence, what makes the comporting towards beings (ontic knowledge) possible is the preliminary understanding of the constitution of being, ontological knowledge. (1997, p. 7)

For Heidegger, and for Kant, it is ontological understanding-an a priori understanding of the being of beings-which makes the ontic understanding of beings in their various determinations possible.

For Heidegger, the possessor of this ontological knowledge is Dasein. Dasein's place in Being and Time's order of explanation entails that the "mathematical project of nature" will be beholden to the mode of being of Dasein as its condition of possibility. As Heidegger puts it,

In whatever way one interprets this being of "nature," all modes of being of innerworldly beings are ontologically founded in the worldliness of the world, and thus in the phenomenon of being-in-the-world. From this there arises the insight that neither does reality have priority within the modes of being of innerworldly beings nor can this mode of being even characterize something like world and Dasein in an ontologically adequate way. (2010, p. 203)

The very intelligibility of the notion of "reality" as applied to the things of naturethe very intelligibility of "reality" as the mode of being of natural things-depends on Dasein's mode of being as being-in-the-world. Because of this, "reality," in the sense proper to the natural sciences, cannot adequately characterize the mode of being of Dasein. That notion of "reality" is not adequate when it comes to determining the mode of being of the world Dasein inhabits, nor is it adequate in determining Dasein's mode of being-in that world-the two structural moments

8 See Glazebrook (2000, ch. 1) for a comprehensive analysis of the role of "mathematical projection" in Heidegger's understanding of science, and for discussion of the origins of that concept in Heidegger's reading of Kant. I place greater emphasis than Glazebrook, here, on examining the role that the question of the mode of being of the subject plays in motivating Heidegger's divergence from Kant, with whom he otherwise largely agrees-see the following section. 
together constitute the mode of being of Dasein as "being-in-the-world." Dasein exists, and in that sense it is real, but it is not "real" in the way that the objects of natural science are "real."

None of this is to say that Heidegger disputes the findings of physics. Heidegger writes in his essay, "The Thing” that, “The statements of physics are correct. By means of them, science represents something real, by which it is objectively controlled." However, "Science always encounters only what its kind of representation has admitted beforehand as an object possible for science” (1971, p. 170).

This puts Heidegger in roughly the same position as Kant with respect to standard forms of naturalism. He cannot be a metaphysical naturalist given that he takes there to be beings that exist in ways that are not countenanced by the natural sciences. For example, a scientific instrument shows up in the physics laboratory as something handy [zuhanden]. It is a piece of equipment [Zeug] constituted within a referential totality [Verweisungsganzheit], and its role is precisely to facilitate theoretical engagement with objectively present [vorhanden] things. ${ }^{9}$ However, the instrument's being as something handy, its showing up as equipment, is not what mathematical physics is aimed at discovering. Indeed, this mode of being as handy, as equipment, is generally "covered over" by a theoretical understanding of things, in favor of their discovery as objectively present. Most crucially, however, and analogous to Kant's "transcendental principles", the mode of being of Dasein, existence [Existenz], the mode of being which makes it possible for equipment to show up in its being, and which makes possible the actual practice of science, generally, is not discoverable by the methods of natural science, and is, likewise, usually covered over by it. Thus, Heidegger, like Kant, makes the justificatory practices of physics dependent on a being that is not itself known through scientific methods: Dasein. He is, therefore, not a methodological naturalist, assuming that this requires the exclusion of all methods of justification beyond those of the natural sciences.

\section{Kant and Heidegger on Subjectivity}

Heidegger argues in Being and Time that Kant's way of articulating the dependence of science on subjectivity is "methodologically naïve." Kant's transcendental

\footnotetext{
9 Cerbone (1999) and McDaniel (2013) defend the view that, for Heidegger, the distinction between handiness and the objective presence represents not just a cognitive or epistemic difference which is relative to our mode of engagement with a thing, but rather a metaphysical or ontological difference belonging to the thing itself, such that the hammer as a handy piece of equipment is numerically distinct from the hammer as objectively present physical stuff.
} 
idealism gets something right in that it understands "the fact that being is never explicable by beings," but,

If idealism means the reduction of all beings to a subject or a consciousness which are only distinguished by the fact that they remain undetermined in their being and are characterized at best negatively as 'unthinglike', then this idealism is methodologically no less naïve than the grossest realism... (2010, p. 200)

Why does Heidegger say this? What is it, in particular, that Kant's transcendental idealism remains naïve about?

To understand this claim, we need to examine Kant's views on the self and selfknowledge. Recall that in the First Critique, in The Paralogisms of Pure Reason chapter, Kant argues that we are given to ourselves, as thinkers, as temporally-structured objects of inner sense-that is, as appearances, not as things in themselves. So while he acknowledges that we necessarily show up to ourselves as thinking, he argues that it does not follow from this that what does the thinking - call it "the soul" - is in itself a simple, unified, and immaterial thinking substance related to the body. To draw this conclusion would be to assume that what goes for appearances goes for things in themselves, a fallacy that gets us lost in the transcendental illusion to which rationalist metaphysics is always vulnerable. Rather, Kant says,

Through this I, or He, or It (the thing), which thinks, nothing further is represented than a transcendental subject of thoughts which is recognized only through the thoughts that are its predicates... (1998, p. 414)

But in addition to showing up to ourselves, as it were, passively, as witnesses of our own experiences passing in time, we are also immediately aware of ourselves as active through what Kant calls "pure apperception.” As Kant puts it in his discussion of the antinomies:

The human being is one of the appearances in the world of sense[...] As such he must accordingly also have an empirical character, just like all other natural things. [...] Yet the human being, who is otherwise acquainted with the whole of nature solely through sense, knows himself also through pure apperception, and indeed in actions and inner determinations which cannot be accounted at all among impressions of sense; he obviously is in one part phenomenon, but in another part, namely in regard to certain faculties, he is a merely intelligible object, because the actions of this object cannot at all be ascribed to the receptivity of sensibility. We call these faculties understanding and reason... (1998, pp. 539f.)

Heidegger's complaint focuses on this last point. What are the faculties? Or, as Heidegger himself asks, echoing a question Kant explicitly sets aside in the Preface to the First Critique, "How is the faculty of thinking itself possible?" (Heidegger 
1997, p. 150; Kant 1998, p. 103). Heidegger's claim is that Kant doesn't allow himself the means to answer this question, with the result that his transcendental idealism must remain methodologically naïve regarding the ontological status of the subjectivity resting at its foundations. Kant fails to give any ontological determination of the faculties (except, perhaps, in the barest profile as functionally and teleologically structured). Kant doesn't offer such a characterization, and in fact, Heidegger argues, he can't. Kant cannot answer the "how possible?" question because, as Heidegger points out, Kant "tries to show quite explicitly that and why the ego's existence, its mode of being, cannot be elucidated” (1988, p. 142).

The point here is a delicate one. While Kant does acknowledge that we have immediate knowledge of ourselves as agents of both thinking and doing, this knowledge does not tell us what entity grounds such activities, what entity acts, what entity grounds knowledge of the self. This was the key result of Kant's arguments against rational psychology in the Paralogisms chapter. As Heidegger reads this section, Kant's conclusion is that:

The pure ego itself is never given to me as a determinable for determination, for applying the categories. For that reason an ontical knowledge of the ego and, consequently, an ontological determination of it is impossible. The only thing that can be said is that the ego is an "I-amacting." (1988, pp. 144f.)

Heidegger's point here is that, on Kant's view, if I am to have theoretical knowledge of myself, I must have it in the form of a determinate spatiotemporal cognition. But such cognitions depend on receptivity for their intuitive matter. Now, since I am not given to myself, as pure ego, through receptivity, but through pure apperception, a form of spontaneity, I will be unable to cognize myself as a thinker in a determinate, spatiotemporal way, and Kant concludes that "I therefore have no cognition of myself as I am, but only as I appear to myself” (1998, p. 260). All that I can say about myself with any certainty, is "I think," or more generally, "I act."10

Now, Heidegger agrees with Kant that it is correct to think that the categories constituting the system of nature are the wrong conceptual tools to characterize our mode of being as Dasein:

Kant is wholly right when he declares the categories, as fundamental concepts of nature, unsuitable for determining the ego. But in that way he has only shown negatively that the

10 This reading of Kant is echoed by Wilfred Sellars in his essay, “...This I or He or It (The Thing) Which Thinks..." Sellars writes that "The idea that concepts pertaining to thinking are essentially functional in character raises the question: What non-functional characterization can be given of the processes which embody these functions. To answer 'They are thoughts' is to move in a circle. Kant's answer is, essentially, that we are not able to give a non-functional characterization. We don't know these processes save as processes which embody these functions" (1970, p. 11). 
categories, which were tailored to fit other beings, nature, break down here. He has not shown that the "I act" itself cannot be interpreted in the way which it gives itself, in this selfmanifesting ontological constitution. (1988, p. 145)

That is,

It does not follow from the inadequacy of the categories of nature that every ontological interpretation whatever of the ego is impossible. That follows only on the presupposition that the same type of knowledge which is valid for nature is taken as the sole possible basis for knowledge of the ego. (1988, p. 146)

Kant assumes that the ego must be known according to the very same system of determinations that apply to nature. But against this assumption, Heidegger claims that Dasein is given to itself in a distinct way. Although Dasein is not given to itself as a natural being in Kant's sense, we can still specify, phenomenologically, the way that it shows up to itself as existing. So, for Heidegger, although we are not given to ourselves as nature is given to us, our being-in-the-world nevertheless discloses a unique and determinate mode of "factical" existence, not merely an indeterminate "activity" as Kant would have it.

Thus, for Heidegger, our subjectivity-our mode of being as Dasein-is not wholly natural, despite its constitution as a determinate, world-embedded existence. As Heidegger states in the heading to $\$ 10$ of Being and Time, the study of Dasein is not "anthropology, psychology, [or] biology," and while Dasein, "can be understood within certain limits and with a certain justification as something merely present," it remains the case that "To do this, one must completely disregard or just not see the existential constitution of being-in" (2010, p. 56). That is, in order to understand Dasein as natural in the restricted sense of the natural sciences, we must remain naïve to what fundamentally characterizes Dasein: the openness to phenomena that constitutes it as being-in-the-world. For Heidegger, then, just as for Kant, the necessity of understanding subjectivity as a nonnatural entity through non-scientific means presents an insuperable barrier to a thoroughgoing naturalism of the standard metaphysical and methodological kinds.

While Heidegger most often identifies the term "nature" with the totality of objectively present [vorhandene] physical objects, he occasionally admits that there are other equally valid senses of the term. ${ }^{11}$ In Being and Time, Heidegger acknowledges that nature can also show up for us in relation to our projects as resource or obstacle: the tree as timber, the river as water power, the wind as filling a sail (2010, p. 70). It can also show up in "the Romantic concept” (2010, p. 65) as a

11 See Storey (2015) and Foltz (1995) for discussion of the different senses of "nature" at work in Heidegger's corpus. 
nature that "stirs and strives," (2010, p. 70) behind and beyond any particular being. According to Heidegger's more expansive understanding of nature, nature manifests itself not just in physics, but pre-theoretically as well, in our everyday engagements with things. Indeed, according to Heidegger, we arrive at the physical conception of nature-at the conception of nature as the totality of objectively present [vorhandene] physical stuff-through a historical process of "de-worlding," which emerges as a disciplined way of dealing with breakdowns in our prior, pre-theoretical engagements.

This suggests that there may be a way to understand Dasein as a natural being without succumbing to the ontological naïveté Heidegger associates with attempts at physicalistic reduction. In his essay "Science and Reflection," Heidegger suggests an understanding of nature, or physis, as encompassing more than what is made available by contemporary physics:

\begin{abstract}
Physics may well represent the most general and pervasive lawfulness of nature in terms of the identity of matter and energy; and what is represented by physics is indeed nature itself, but undeniably it is only nature as the object-area, whose objectness is first defined and determined through the refining that is characteristic of physics and is expressly set forth in that refining. Nature, in its objectness for modern physical science, is only one way in which what presences-which from of old has been named physis-reveals itself and sets itself in position for the refining characteristic of science. (1977, pp. 173f.)
\end{abstract}

If we understand nature as that "which from of old has been named physis," then nature does not consist only in physical nature; it becomes that which brings itself to presence in all the various ways that this can happen, both in the natural sciences, and in Dasein's grasp of itself as the being concerned with its own being. ${ }^{12}$ Padui (2013) argues that understanding nature in this way, as encompassing a plurality of modes of being, opens up the possibility of understanding Dasein itself as a natural being, without conceiving of it, in reductive fashion, as an objectively present physical thing. Crucially, this satisfies a key naturalist desideratum, namely that the predicate "natural" be understood in a non-contrastive way, as referring to the mode of being of all existing beings, instead of just referring to the mode of being of some, carving out one side of a dichotomy, e. g., the natural vs. the artificial, the natural vs. the cultural, etc. Since all beings are grounded on nature, all beings are natural, without remainder.

12 Attempts to recover a supposedly "originary" concept of nature from the ancient Greeks can be found throughout Heidegger's work. An especially clear and focused example can be found in "On the Essence and Concept of Physis in Aristotle's Physics B, I” (Heidegger 1998). For examinations of Heidegger's reappropriation of the concept of physis from the ancient Greeks see Storey (2015), Glazebrook (2000, ch. 4), Haar (1993, ch. 4), Zimmerman (2003), and Foltz (1995). 


\section{Can a Transcendental Subject be a Being?}

In the late 1920s, after the publication of Being and Time, Heidegger introduced a companion science to fundamental ontology which he called "metontology." Where fundamental ontology sought to ground the possibility of ontological knowledge in an interpretation of the mode of being of Dasein, metontology, by contrast, sought to ground the existence of Dasein in the conditions that make possible its mode of being. While the project of metontology might seem anodyne at first glance (what could be more obvious than the dependence of Dasein on some further, more fundamental conditions?), it raises a number of deep methodological issues that are worth considering.

For Heidegger, the question of the meaning of being can only come into proper focus if we distinguish the question of what it is for things to exist in general from the question of what it is for this or that specific thing to exist-i. e., if we distinguish the ontological from the ontic, being from beings. But the ontological difference between being and beings is intelligible only on the basis of Dasein's understanding of the being of beings, an understanding that is exemplified in its everyday circumspect dealing with beings as beings of this or that kind. This has the consequence that ontology, the science of being, is possible only if Dasein exists, and this, Heidegger observes, requires "the factual extantness of nature" (1984, p. 156). Dasein's understanding, its grasp of everything from hammers to hadrons, is possible only "if a possible totality of beings is already there" (1984, p. 157). Thus, Heidegger characterizes metontology as the turning back of ontology towards its own origins in "a possible totality," a turning back which provides a necessary supplement to fundamental ontology by explicating, in more detail, the chain of dependencies just outlined.

As others have noted, Heidegger's distinction between fundamental ontology and metontology echoes Kant's appropriation of the Wolffian distinction between general and special metaphysics in the architectonic structure of the Critique (Crowell 2001, ch. 12; Reichl 2018). Kant effects a transformation of general metaphysics into transcendental philosophy (inquiry into the conditions of a priori knowledge in general), and special metaphysics into rational physiology (the system of a priori knowledge applied to different species of beings) (1998, p. 698). If Heidegger's fundamental ontology is the successor to Kant's transcendental philosophy, then metontology would be the successor to rational physiology. Crucially, Kant's reinscription of the topics of special metaphysics-rationalist cosmology, psychology, and theology-in the context of transcendental idealism has the result of limiting the scope of those sciences to phenomena: our attempts to cognize the cosmos, the soul, and God on the basis of pure reason fail to provide 
knowledge of things in themselves, and, even with respect to phenomena, never provide the complete set of intuitions that would be needed for cognition of the relevant objects.

For Kant, then, no theoretical knowledge of the metaphysical ground of transcendental subjectivity is possible, since this would require cognitions going beyond the bounds of sense. Heidegger's metontology, however, seems to seek knowledge of exactly such a ground: a "metaphysical ontic" (1984, p. 158) that explains, at a more fundamental level than the analytic of Dasein, why "the possibility that being is there in the understanding presupposes the factical existence of Dasein," and why "this, in turn, presupposes the factual extantness of nature" (1984, p. 156). But just as inquiry into the metaphysical ground of transcendental subjectivity must be confused by Kant's lights, leading only to transcendental illusion, it seems that it should also be confused by Heidegger's lights, blurring the ontological difference, thereby leading back to an "ontotheology" of a highest being serving as the ultimate metaphysical ground of the totality of beings. This has led some to suggest that Heidegger's attempt to supplement fundamental ontology is simply confused, a project doomed from the very start. Steven Crowell, for instance, argues that Heidegger's renewed engagement with the question of metaphysical origins in the late 1920s and early 1930s "appears suspiciously like the search for an ontic 'explanation' for beings as a whole, one that threatens to annul his genuine insight into the difference between being (meaning) and beings" (2001, p. 231). Pavel Reichl (2018) defends Heidegger against this charge, making a plausible case that what Heidegger is really after in metontology is not an ontic explanation of Dasein and its relation to the extant totality of beings, but instead, a ground that explains the unity and possibility of all possible modes of being, a ground that Heidegger hoped to find in his phenomenological account of temporality.

Whether or not Heidegger's attempt to provide a unified temporal ground for all possible modes of being can be counted a success, Heidegger's search for a nonobjectual ground of Dasein's mode of being raises a puzzling question: is it coherent to take Dasein-insofar as it is the condition of the intelligibility of beings-to be a being, even if one of a special kind? In trying to understand the condition of the intelligibility of the world as a worldly being aren't we making the mistake of objectifying transcendental subjectivity?

Eugen Fink, Husserl's student and eventual collaborator, pressed precisely this concern regarding the coherence of conceiving transcendental subjectivity as a being in his Sixth Cartesian Meditation, which was written as a methodological addendum to Husserl's five-part Cartesian Meditations. Curiously, Fink's criticisms of Heidegger's ontology of Dasein parallel Heidegger's own criticisms of Kant's transcendental idealism as “methodologically naïve.” Fink accuses Heidegger of 
naïveté in attempting to move directly from phenomenological reflection on the conditions of possibility of world-experience to ontological determination of those very conditions. ${ }^{13}$ Fink complains that "Having overcome world naiveté we stand now in a new naiveté, a transcendental naiveté” (1995, p. 5). Fink's worry reiterates the impulse of transcendental philosophy to seek the conditions of possibility for all our cognitions, this time with respect to our cognition of the very transcendental structures that transcendental philosophy itself thematizes. Fink argues that the phenomenological understanding of transcendental subjectivity has not itself been adequately scrutinized with respect to its conditions of possibility. This is to say that beyond explaining how it is possible for beings to be given to us, phenomenology owes us an explanation of how it is possible for transcendental subjectivity to be given to us. As Fink writes in the Sixth Cartesian Meditation:

It is the proper task of the transcendental theory of method to make phenomenologically understandable the whole systematic of phenomenological inquiry, the structure of methodological procedure, the rank and style of transcendental cognition and "science." Its task, therefore, is to submit the phenomenologizing thought and theory-formation [...] to a proper transcendental analytic, and thus to complete phenomenology in ultimate transcendental self-understanding about itself. In other words, the transcendental theory of method intends nothing other than a phenomenology of phenomenology. (1995, p. 8)

The task then, is to provide a phenomenological account of the conditions of possibility of phenomenology.

Fink sides with Kant against Heidegger in thinking that transcendental subjectivity cannot be manifest to itself in a way that allows for conclusive ontological determination of its mode of being. Like Kant, Fink argues that theoretical cognition is limited to objects given to us as existent beings: "All natural cognition is cognition of what is existent, all experience is experience of what is existent. [...] There can in principle be no other object of cognition than what is existent" (Fink 1995, pp. 70f.). Given this limitation, if transcendental cognition is to be a valid form of theoretical cognition, then it too must have an existent for its object. Fink argues, however, that in transcendental cognition we are not given to ourselves as existent. Why not? Because "What is 'existent' in the natural and thus in the original sense is the existent which is to be met with in the horizon and circuit of the natural attitude: that which is existent in the world" (Fink 1995, p. 72). The notion of the existent applies only to what we find in the world, to natural, mundane existence, and for this reason, it cannot be applied, strictly speaking, to the worldconstituting transcendental structures of subjectivity that we discover in

13 See Bruzina (2004, ch. 3) for an exceedingly thorough reconstruction of Fink's criticisms of Heidegger. 
phenomenology. Because the concept of existence originates in the natural attitude, Fink concludes that the concept of existence is properly applied only to what is constituted for the subject in the natural attitude, i. e., what shows up in mundane world-experience.

But if transcendental cognition does not have an existent for its object, how can it provide us with knowledge? In order to explain this, Fink argues that in phenomenological reflection, transcendental subjectivity produces an "appearance" of itself as existent, without being strictly identical to this appearance. Transcendental cognition is cognition of transcendental appearance, but transcendental appearance is not identical with transcendental subjectivity itself. According to Fink, in ordinary world-experience the world is given as a totality of constituted beings through the "primary" or "proper enworlding" of transcendental subjectivity (1995, p. 99). Through this enworlding, the transcendental subject, "spellbound" and "captivated" by mundane being, identifies itself with the empirical ego-the human being-thereby "imprisoning" itself in the constituted world of the existent. ${ }^{14}$ In phenomenological reflection, however, by means of the transcendental epochē and reduction, we are able to "transcend" our merely human existence, transforming our captivated experience of existent beings in the natural attitude into an awareness of existent beings as constituted for the transcendental ego. This phenomenological reflection involves a "secondary" or "improper enworlding," which "places phenomenologizing itself into the world, that is, into the natural attitude, it 'localizes' and 'temporalizes' it there; in other words, it makes it 'appear' in the world” (1995, p. 99). In this secondary and "improper" enworlding, the transcendental subject experiences itself, here and now, as transcendentally constituting the existent beings it encounters.

To whom is this experience given? Fink argues that in the "improper" enworlding that is constitutive of phenomenological reflection, we take on the role of transcendental or phenomenological "onlooker" with respect to the constituting transcendental ego. For Fink, phenomenological reflection involves not only a constituting transcendental ego and a constituted empirical ego, but a "transcendental onlooker" as well, for whom the constituting transcendental ego can appear. These three egos together constitute the internal structure of the transcendental subjectivity that makes phenomenological reflection possible.

It remains, however, that the constituting transcendental ego which appears in the experience of the transcendental onlooker is not a worldly being, a thing

14 As Crowell (2001, ch. 13) notes, Fink's understanding of transcendental subjectivity has a deeply Gnostic cast to it, making human existence into a prison, from which we can escape only through the "dehumanizing" enaction of the transcendental epochē. For Fink, the transcendental epochē reveals our true nature as transcendental subjects to be fundamentally inhuman. 
existent in the world. The secondary enworlding of the transcendental subject remains "improper." To say that the transcendental ego exists in some way, that it exhibits a mode of being, would be, strictly speaking, inaccurate: "We have to make clear to ourselves that 'transcendental being,' as a counter-concept to 'natural' or 'worldly being,' is not a kind of being at all' (1995, p. 72). For Fink, the notion of "transcendental being" is dangerously equivocal because the appearance of the transcendental ego remains conditioned by the "mundane idea of being"-the idea of being as what exists in the world. Even after the transcendental epochē,

\begin{abstract}
we have not for the most part got beyond captivation in the mundane Idea of being. Ensnared in it we interpret what comes to givenness for us through the phenomenological reduction [...] as a sphere of "transcendental" being. Although necessary, this is a phenomenological naïveté insofar as, under the covert guidance of the natural concept of being not yet properly overcome, we at first seek to grasp transcendental being as an autonomous dimension of the existent which as such represents the substrate of our theoretical-phenomenologizing experience. We are caught in the quite obvious belief that transcendental being would be a new mode of being discovered precisely by the reduction, one now to be set alongside the mode of being of mundane being. (Fink 1995, p. 72)
\end{abstract}

Fink admits that while the constituting transcendental ego certainly appears to us by means of the reduction, the thought that it must exist in some way, must possess a unique mode of "transcendental being," results from an interpretation of phenomenological experience in terms of, and by analogy with mundane being, the mode of being of what is existent in the world. But while this analogical way of understanding transcendental subjectivity is ultimately inadequate in determining its object, we nevertheless have no alternative to it: "we must posit transcendental subjectivity just as if it were something existent. We have no other possibility for disclosing and explicating it, if we do not thematize it following the guidance through analogy of the Idea of being" (Fink 1995, p. 74).

Fink's transcendental theory of method is thoroughly determined by his delimitation of the concept of being according to the mundane mode of being discovered in the natural attitude. Since transcendental cognition is not knowledge of that kind of being, Fink is forced to invent a new conceptual category for the proper "object" of phenomenological reflection. Fink's proposal is that transcendental cognition is concerned with something altogether different from being: it is concerned with processes of "pre-being," rather than being. What makes possible both the constitution of the world and the awareness of this constitution is not itself a being, but a "pre-being." Pre-being, while not an existent being, must be thought analogously to existent being. This, however, does not give pre-being as it "is" in itself. Caught between the imperative to cognize transcendental subjectivity as world-constituting, and the thesis that our cognition can only make the 
constituting transcendental ego available on the basis of a faulty analogy with mundane being, Fink concludes that

\begin{abstract}
phenomenological experience does not cognize something which is already existent, as what and how it is; it cognizes the sort of thing which is "in itself" not existent; in cognizing it it objectifies it into something that is (transcendentally) "existent," it lifts the constitutive construction-processes [DS: i.e., the processes that transcendentally constitute mundane existence] out of the condition of "pre-being" proper to them and for the very first time in a certain sense objectivates them. In other words, the theoretical experience of the phenomenological onlooker ontifies the "pre-existent" life-processes ${ }^{15}$ of transcendental subjectivity... (1995, p. 76)
\end{abstract}

Just as in Kant's transcendental dialectic, the attempt to think the ultimate conditions of the possibility of experience as beings leads us to deploy concepts that "objectivate" and "ontify" those conditions, circumscribing them in ways that are ultimately inappropriate and misleading since the features they attribute do not and cannot properly belong to their objects. Nevertheless, Fink thinks, as Kant does, that we cannot eliminate this kind of thinking since we cannot rationally give up the aim of trying to cognize the unconditioned conditions of our experience.

While Kant stops at this point, thinking that any further move to characterize the unconditioned can lead only to dialectical illusion, Fink argues that we can surpass the Kantian predicament by embracing a "constructive" resolution of the impasse. While our thinking does not and cannot give us intuitively grounded knowledge of the unconditioned conditions of phenomenological experience, Fink's proposal is that we can generate positive knowledge of the absolute ground of phenomenological experience, despite its lack of intuitive givenness, through what he calls a "constructive phenomenology":

What is required here is rather a whole movement out beyond the reductive givenness of transcendental life, what is required is an examination of the "external horizon of the reductive givenness" of transcendental life[...] An examination of this kind, however, insofar as it abandons the basis of transcendental "givenness," no longer exhibits things intuitively, but necessarily proceeds constructively. (Fink 1995, p. 7)

In constructing a concept of the absolute, we come to see the constituted being of the existent, as well as the appearance of constituting subjectivity for the transcendental onlooker, as two necessary components, or interdependent "moments," in the realization of an absolute condition which encompasses both:

the Absolute is precisely the unity of transcendental constitution and the transcendental process of phenomenologizing. That is, the Absolute is the overarching total unity of

15 i. e., the processes involved in experiential life, not biological life-processes. 
transcendental life as a whole, which in itself is articulated into opposites. This division between constituting and phenomenologizing life determines now the concept of the Absolute: the Absolute is the synthetic unity of antithetic moments. (Fink 1995, p. 142)

In phenomenology, Fink argues, the Absolute, is knowable precisely as the inexperienceable external horizon of all experience. The Absolute is the root of both our awareness of constituted mundane existence and our awareness of the constituting transcendental ego.

\section{Nature as the Ground of Phenomenal Manifestation}

Fink's Sixth Cartesian Meditation defends a more formal, Husserlian conception of transcendental subjectivity against a more concrete, Heideggerian conception of subjectivity as being-in-the-world, arguing that only the Husserlian conception can properly account for the possibility of phenomenology. For Fink, phenomenology is not a method for disclosing the mode of being of concrete Dasein. Instead, phenomenological reflection generates only the appearance of a transcendental subject, an appearance that can be understood, on the basis of "constructive phenomenology," as grounded in an inexperienceable Absolute which is prior to being.

But do we really need a novel concept of "pre-being" in order to account for the origins of subjectivity, or does the concept of being already extend to the ground of phenomenological reflection? Is it really the case that because the concept of being finds its original home in the world of mundane existence that mundanity must remain its only and proper home?

The beginnings of a Heideggerian response to Fink's view lies in Heidegger's understanding of Dasein's relationship to the being of beings as a form of transcendence. For Fink just as much as for Husserl, beings only show up in virtue of their ability to be "contained" immanently in transcendental consciousness, the experiential field of the transcendental subject. For Heidegger, by contrast, it is not immanence to transcendental subjectivity which characterizes the givenness of beings, but the being of subjectivity as the transcendence of the self to what it is not the self. Dasein's mode of being is to be always already "outside of itself" (2010, p. 314 ) in its encounters with objects, objects whose very independence and externality from subjectivity are constitutive of Dasein's own finite and dependent mode of being-in-the-world. Dasein constitutes the world from within the world, and in necessary dependence upon it. Fink locates the original unity-in-difference that makes possible the relation of subject and world in a "pre-being" which produces 
that opposition. From a Heideggerian point of view, however, the introduction of the concept of "pre-being," is unnecessary. In being what it is, Dasein is not simply itself, but already involves, in its very mode of being, a relation to what is other than itself.

What then, about the original productivity, the temporalizing of temporality, which Heidegger takes to be the ontological ground of Dasein's being-in-theworld? In attempting to understand this productivity we come once again to the very limits of phenomenological method.

Merleau-Ponty, in his later work, wrestled with these limits, attempting to bring to them some coherent articulation. Merleau-Ponty argues that at this limit, we discover nature as the ultimate ontological ground of phenomenological experience. In "The Philosopher and His Shadow," a late commentary on Husserl, Merleau-Ponty writes,

the ultimate task of phenomenology as philosophy of consciousness is to understand its relationship to non-phenomenology. What resists phenomenology in us-natural being, the "barbarous" source Schelling spoke of-cannot remain outside phenomenology and should have its place within it. (1964, p. 178)

Here, Merleau-Ponty calls that which exceeds phenomenology, "natural being." Rather than privileging the world-constituting activity of transcendental subjectivity as the precondition for natural being, Merleau-Ponty sides with Schelling in privileging nature as the necessary ground of the transcendental subjectivity that comes to know it. As Schelling puts the point, "It is not... that we know Nature as a priori, but Nature is a priori" (2004, p. 198). It is not our knowledge of nature that must come first in the order of explanation; rather we must acknowledge that nature is first in the order of being. Nature is not just a transcendental presupposition of world-experience; it is its ontological origin. This nature is not the nature of natural science, and neither is it the constituted nature that is product and correlate of the activities of the transcendental subject. The phenomenological attempt to understand nature as the "barbarous source" is "neither simple reflection on the immanent rules of the science of Nature, nor recourse to Nature as to one separated and explanatory Being, but rather explicitation of what beingnatural or being naturally means” (Merleau-Ponty 2003, p. 206). Merleau-Ponty’s phenomenological naturalism is not merely a Kantian reflection on the conditions of the possibility of natural science, nor a post-Kantian attempt to demonstrate that the phenomenal world is produced from a nature that is its "absolute" metaphysical ground. Rather, the investigation of nature is, as Merleau-Ponty says, an "explicitation" of a productivity that is never simply identical with its product, a drawing out of the various ways in which nature allows for the manifestation of natural beings. 
Fink is right that phenomenology cannot bring its own origin into view as an objectively present being, but wrong to think that this implies that the origin must be prior to being, otherworldly, and unnatural. That phenomena become manifest out of an inexperienceable source is just what it is for beings to be; it is the meaning of being, not the trace of something prior to being; not something otherworldly, but the natural world coming to be; not unnatural, but nature uncovering the denizens of its all-encompassing domain. In rediscovering nature outside of science and outside of phenomenology as the phenomenologically-unavailable ontological ground of all phenomena, nature "itself" shrinks to a vanishing point at the origin of both the manifest world and phenomenological reflection.

This allows for a distinctively phenomenological understanding of the meaning of "naturalism." Instead of a metaphysical naturalism, committed to understanding nature as a totality of scientifically-investigable entities, processes, and properties, we can adopt a phenomenological naturalism, committed to investigating a nature which consists in processes of phenomenal manifestation. ${ }^{16}$ Naturalistic explanation becomes the attempt to explicate how natural being manifests itself in phenomenology, just as in physics. Drawing out connections between phenomena, empirically and phenomenologically, is the explicitation of natural being, the project of a phenomenological naturalism.

Acknowledgments: Thanks to Evan Thompson, G. Anthony Bruno, Samantha Matherne, Alva Noë, and two anonymous reviewers at this journal for their comments on earlier drafts.

\section{References}

Bannon, B.E. (2014). From Mastery to Mystery: A Phenomenological Foundation for an Environmental Ethic (Athens, OH: Ohio University Press).

Bruzina, R. (2004). Edmund Husserl and Eugen Fink: Beginnings and Ends in Phenomenology, 1928-1938 (New Haven, CT: Yale University Press).

Cerbone, D.R. (1999). “Composition and Constitution: Heidegger's Hammer," Philosophical Topics 27 (2): 309-329.

Crowell, S.G. (2001). Husserl, Heidegger, and the Space of Meaning: Paths Toward Transcendental Phenomenology (Evanston, IL: Northwestern University Press).

16 On this point, phenomenological naturalism differs quite starkly from attempts to "naturalize phenomenology" by grounding transcendental-phenomenological structures in the properties uncovered by the natural sciences. For examples of the "naturalizing phenomenology" approach see Petitot et al. (1999), and Wheeler (2005). As I've argued elsewhere, however, attempts to naturalize phenomenology are problematic on both metaphysical and methodological grounds (Suarez 2017a). By contrast, the phenomenological naturalism I recommend pursues the opposite strategy of "phenomenologizing nature" (Suarez 2017b; Thompson 2004; Zahavi 2004). 
Fink, E. (1995/1988). Sixth Cartesian Meditation: The Idea of a Transcendental Theory of Method, trans. R. Bruzina (Bloomington, IN: Indiana University Press).

Foltz, B.V. (1995). Inhabiting the Earth: Heidegger, Environmental Ethics, and the Metaphysics of Nature (Atlantic Highlands, NJ: Humanities Press).

Glazebrook, T. (2000). Heidegger's Philosophy of Science (New York, NY: Fordham University Press).

Haar, M. (1993/1985). The Song of the Earth: Heidegger and the Grounds of the History of Being, ed. and trans. R. Lilly (Bloomington, IN: Indiana University Press).

Heidegger, M. (1971). Poetry, Language, Thought, trans. A. Hofstadter (New York, NY: Harper \& Row).

Heidegger, M. (1977). The Question Concerning Technology, and Other Essays, trans. W. Lovitt (New York, NY: Harper \& Row).

Heidegger, M. (1984/1978). The Metaphysical Foundations of Logic, trans. M. Heim (Bloomington, IN: Indiana University Press).

Heidegger, M. (1988/1975). The Basic Problems of Phenomenology, trans. A. Hofstadter (Bloomington, IN: Indiana University Press).

Heidegger, M. (1997/1929). Kant and the Problem of Metaphysics, trans. R. Taft (Bloomington, IN: Indiana University Press).

Heidegger, M. (1998/1967). 'On the essence and concept of physis in Aristotle's Physics B, l', trans. T. Sheehan, in W. McNeill (ed.). Pathmarks (New York, NY: Cambridge University Press), pp. 183-230.

Heidegger, M. (2010/1927). Being and Time: A Revised Edition of the Stambaugh Translation, trans. J. Stambaugh \& D.J. Schmidt (Albany, NY: State University of New York Press).

Kant, I. (1998/1781/1787). Critique of Pure Reason, trans. P. Guyer \& A. Wood (New York, NY: Cambridge University Press).

Kant, I. (2002). Theoretical Philosophy After 1781, trans. G. Hatfield, M. Friedman, H. Allison, \& P. Heath, eds. H. Allison and P. Heath. (New York, NY: Cambridge University Press).

McDaniel, K. (2013). “Heidegger's metaphysics of material beings," Philosophy and Phenomenological Research 86 (1): 332-357.

McNulty, M.B. (2017). “What is chemistry, for Kant?” Kant Yearbook 9 (1): 85-112.

Merleau-Ponty, M. (1964/1960). Signs, trans. R.C. McCleary (Evanston, IL: Northwestern University Press).

Merleau-Ponty, M. (2003/1968). Nature: Course Notes from the Collège de France, trans. D. Séglard (Evanston, IL: Northwestern University Press).

Padui, R. (2013). "From the facticity of Dasein to the facticity of nature: naturalism, animality, and metontology," Gatherings: The Heidegger Circle Annual 3: 50-75.

Petitot, J., Varela, F., Pachoud, B., and Roy, J.-M. (eds.). (1999). Naturalizing Phenomenology: Issues in Contemporary Phenomenology and Cognitive Science (Stanford, CA: Stanford University Press).

Quine, W.V. (1995). “Naturalism; or, living within one’s means,” Dialectica 49 (2-4): 251-263.

Reichl, P. (2018). "Heidegger's reassessment of Metaphysica Specialis and the status of metontological inquiry in the Late Marburg Period," Research in Phenomenology 48 (2): 265-285.

Schelling, F.W.J. (2004/1799). First Outline of a System of the Philosophy of Nature, trans. K.R. Peterson (Albany, NY: SUNY Press).

Sellars, W. (1970). “...This I or he or it (the thing) which thinks...” Proceedings and Addresses of the American Philosophical Association, 44: 5-31. 
Storey, D.E. (2015). Naturalizing Heidegger: His Confrontation with Nietzsche, His Contributions to Environmental Philosophy (Albany, NY: SUNY Press).

Suarez, D. (2017a). “A dilemma for Heideggerian cognitive science," Phenomenology and the Cognitive Sciences, 16 (5): 909-930.

Suarez, D. (2017b). “Phenomenological naturalism," International Journal of Philosophical Studies, 25 (4): 437-453.

Thompson, E. (2004). "Life and mind: from autopoiesis to neurophenomenology. A tribute to Francisco Varela," Phenomenology and the Cognitive Sciences, 3 (4): 381-398.

Wheeler, M. (2005). Reconstructing the Cognitive World: The Next Step (Cambridge, MA: MIT Press).

Zahavi, D. (2004). "Phenomenology and the project of naturalization," Phenomenology and the Cognitive Sciences, 3 (4): 331-347.

Zimmerman, M.E. (2003). 'Heidegger, phenomenology, and contemporary environmentalism', in C.S. Brown and T. Toadvine (eds.). Eco-phenomenology: Back to the Earth Itself (Albany, NY: SUNY Press), pp. 73-101. 